\title{
Editorial Comment: Laparoscopy versus robotic-assisted pyeloplasty in children: preliminary results of a pilot prospective randomized controlled trial
}

\author{
Silay MS ${ }^{1,2}$, Danacioglu $\mathrm{O}^{3}$, Ozel K ${ }^{4}$, Karaman $\mathrm{MI}^{3}$, Caskurlu $\mathrm{T}^{3}$ \\ 1 Department of Pediatric Urology, Istanbul Gelisim University \& Istanbul Memorial Hospital, Istanbul, Turkey; ${ }^{2}$ Istanbul \\ Bahcelievler Memorial Hastanesi, Bahcelievler, Istanbul, Turkey; ${ }^{3}$ Department of Urology, Istanbul Medeniyet University, \\ Istanbul, Turkey; ${ }^{4}$ Department of Pediatric Surgery, Istanbul Medeniyet University, Istanbul, Turkey
}

World J Urol. 2019 Aug 22. [Epub ahead of print]

DOI: 10.1007/s00345-019-02910-8 | ACCESS: 10.1007/s00345-019-02910-8

Eliney F. Faria ${ }^{1}$

${ }^{1}$ Serviço de Urologia, Hospital Felicio Rocho, Belo Horizonte, MG, Brasil

\section{COMMENT}

This interesting paper reported a prospective randomized controlled trial (RCT) about laparoscopic and robotic pyeloplasty in the treatment of ureteropelvic junction obstruction (UPJO) in children. They addressed if the robotic-assisted laparoscopic pyeloplasty (RALP) has additional advantages over conventional laparoscopic pyeloplasty (LP) regarding suturing, comfort for the surgeon and visualization. The main disadvantage of RALP is its higher cost $(1,2)$. This is the first RCT comparing LP and RALP in pediatric population. In a period of 2 years, a total of 53 children (0-18 years old) with UPJO were enrolled into the RCT for either LP or RALP (Group 1, n: 27 - Group 2, n:26). The presence of crossing vessel was identified in 7 (25.9\%) patients for LP group and in 6 (23.1\%) patients for RALP group. Mean total operative time in LP group was $139.26 \pm 43.21 \mathrm{~min}(80-250 \mathrm{~min})$ compared to $105.19 \pm 22.87 \mathrm{~min}(70-150 \mathrm{~min})$ in RALP group ( $\mathrm{p}=0.001$ ). The number of the trocar placement was significantly less in LP group (mean $3.00 \pm 0$ ) compared to RALP group (mean $3.81 \pm 0.40)(p=0.001)$. The mean cost of RALP was higher than LP (p $=0.001$ ). They completed successfully all cases with none converted to open surgery. Postoperative complication rates were similar for both groups in the follow-up period. They reported overall success rate of $96.2 \%$, similar to previously published series of minimally invasive pyeloplasty. Accordingly, robotic procedures had approximately four times higher cost than conventional laparoscopy (3). Despite small number of patients there was a as a pilot study, they reported a RCT and their findings are important to demonstrate the comparison of LP and RALP in children. The short-term results reveals that both LP and RALP are safe and effective in children with comparable success and complication rates. 


\section{CONFLICT OF INTEREST}

None declared.

\section{REFERENCES}

2. Tasian GE, Casale P. The robotic-assisted laparoscopic pyeloplasty: gateway to advanced reconstruction. Urol Clin North Am. 2015;42:89-97.

1. Radmayr C, Bogaert G, Dogan HS. EAU Guidelines on paediatric urology. Edn. presented at the EAU Annual Congress Barcelona. 2019. Available at. <https://uroweb.org/wp-content/uploads/ EAU-Guidelines-on-Paediatric-Urology-2019.pdf>

3. Cundy TP, Harling L, Hughes-Hallett A, Mayer EK, Najmaldin AS, Athanasiou T, et al. Meta-analysis of robot-assisted vs conventional laparoscopic and open pyeloplasty in children. BJU Int. 2014;114:582-94.

\section{Eliney F. Faria, MD}

Serviço de Urologia, Hospital Felicio Rocho, Belo Horizonte, MG, Brasil

E-mail: elineyferreirafaria@yahoo.com.br

ARTICLE INFO

(iD) Eliney Faria https://orcid.org/0000-0002-8297-3417

Int Braz J Urol. 2020; 46: 655-6 